Szczepan M. Biliński · Jerzy Klag Janusz Kubrakiewicz

\title{
Subcortical microtubule network separates the periplasm from the endoplasm and is responsible for maintaining the position of accessory nuclei in hymenopteran oocytes
}

Roux's Arch Dev Biol (1995) 205:54-61

On page 56 of the above article the incorrect version of Figs. $1-5$ and there legends was printed, so the correct plate is reprinted below for your convenience.

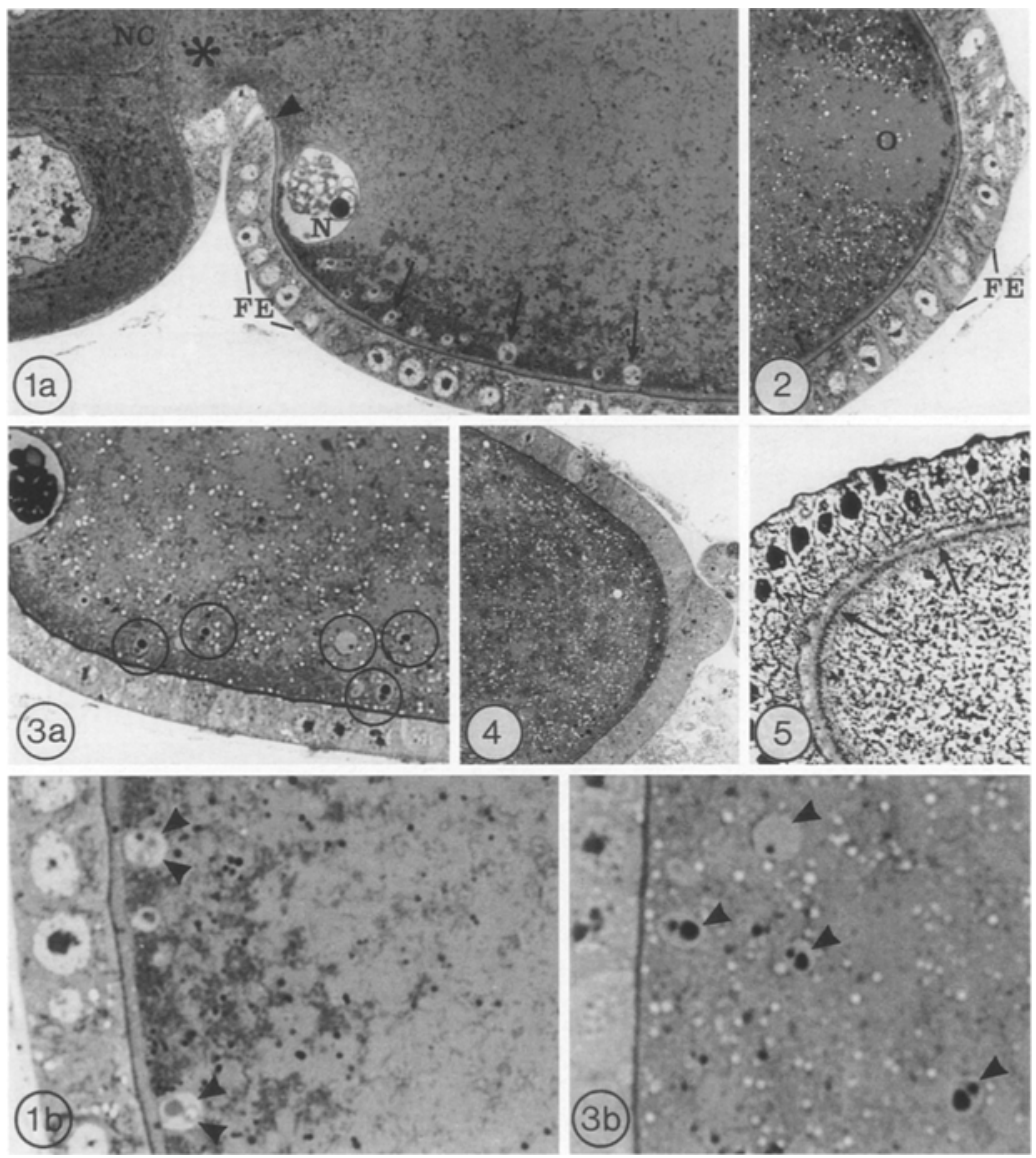

Figs. 1-5 Chrysis ignita

Fig. 1a Light micrograph of the anterior pole of the oocyte ( $F E$ follicular epithelium, $N C$ nurse cells, $N$ oocyte nucleus, arrows accessory nuclei, asterisk indicates nutritive appendix). Note that the periplasm terminates at the base of the appendix (arrowhead). Dense particles accumulated next to the periplasm represent mitochondria. $\times 700$. b Larger magnification of a fragment of a. Accessory nuclei (arrowheads) are flattened in contact with the transparent periplasm. $\times 1,400$

Fig. 2 Light micrograph of the posterior pole of the oocyte ( $F E$ follicular cells, $O$ oosome). Note the periplasm and lipid droplets (small, transparent vesicles). $\times 700$
Fig. 3a Light micrograph of the anterior pole after colchicine treatment. Note the distribution of lipid droplets (small transparent vesicles) and accessory nuclei (encircled). $\times 850$. b Larger magnification of a fragment of a. The periplasm is not recognizable, accessory nuclei (arrowheads) are scattered in the ooplasm at different distances from the oolemma. $\times 1,400$

Fig. 4 Light micrograph of the posterior pole after colchicine treatment. Note the absence of the oosome. $\times 450$

Fig. 5 Light micrograph of an oocyte and enveloping follicular epithelium after Triton X-100 extraction. Section oblique to the oocyte surface. Two cytoskeletal layers are recognizable (arrows) 